\title{
Suicide of isolated inmates suffering from psychiatric disorders: when a preventive measure becomes punitive
}

\author{
S. Grassi ${ }^{1}$ - G. Mandarelli ${ }^{2}$ - M. Polacco $^{1}$ - G. Vetrugno $^{3}$ • A. G. Spagnolo ${ }^{4}$. \\ Fabio De-Giorgio ${ }^{1}$
}

Received: 16 February 2017 / Accepted: 11 October 2017 / Published online: 19 October 2017

(C) Springer-Verlag GmbH Germany 2017

\begin{abstract}
We performed external autopsies and examinations on two inmates who had committed suicide by hanging themselves with their underwear and using the window bars of their cells as ligature points after they had been placed in solitary confinement. In one case, the inmate had even been deprived of her clothing (with the exception to her underwear). Underwear has been rarely described as a means for selfharm and, to the best of our knowledge, no previous study has focused on cases of prison suicides committed using this garment, even though it is available to every inmate. The two cases were very similar; both inmates were young, physically aggressive and in their first week at a new facility; both had been affected by mental disorders, had been prescribed psychotropic medications and had histories of psychiatric hospitalisation. In each case, the psychiatric evaluations had highlighted significant suicidal risk. We discuss these two cases in an attempt to describe the complexity of and contradictions within the management of suicidal inmates at correctional facilities. We aim to propose new strategies and emphasise the need to introduce evidence-based standardised protocols over inhumane, ineffective and simplistic punitive measures in the management of these individuals.
\end{abstract}

Fabio De-Giorgio

fabio.degiorgio@unicatt.it

1 Institute of Public Health, Section of Legal Medicine, Università Cattolica del Sacro Cuore, Rome, Italy

2 Department of Neurology and Psychiatry, University of Rome, Sapienza, Rome, Italy

3 Unit of Risk Management, Policlinico A. Gemelli, Rome, Italy

4 Institute of Bioethics, Università Cattolica del Sacro Cuore, Rome, Italy
Keywords Prison suicide $\cdot$ Hanging $\cdot$ Underwear $\cdot$ Solitary confinement

\section{Introduction}

Prison suicide has become a major public issue that has reached epidemic proportions in Western countries. It is a phenomenon that can affect the entire prison community; both inmates and correctional officers are more vulnerable to suicide than the general population [1-7]. In Italy, there were 7.2 suicides per 10,000 inmates in 2016, a rate which was lower than the averages for the previous 23 years (except for 2013) [8]. This rate is also lower than those of other European countries, such as the United Kingdom (UK), which in 2016 reported a rate of 1.4 suicides per 1000 prisoners [9].

In the scientific literature, the following predictors of suicide, some of which are prison specific, have been determined: drug and alcohol abuse, psychiatric disorders, a history of suicidality, the use of psychotropic medications, single-cell accommodations, social and financial problems, age ranging being between 18 and 44 and long sentences after committing highly violent crimes $[1,5,10,11]$.

Sudden social isolation and a new prison environment are particularly significant factors: most prison suicides occur within the first year of detention (primarily during the first days or weeks of imprisonment) $[1,5,11]$. Solitary confinement is commonly used to further segregate individuals who can be dangerous to themselves and others, even though both temporary and permanent isolation have been recognised to be predictors of suicide in prisoners [12].

The following psychological factors are associated with increased risks of near-lethal suicide attempts: aggression, hopelessness, impulsiveness, low self-esteem and depressive symptoms [7]. Therefore, it is clear that resilience (i.e. 
the personal capacity to successfully adapt to adverse situations) plays a fundamental role in a prisoner's ability to cope with the stressful environment of prison and its implications on daily life.

Psychiatric disorders and the abuse of drugs or alcohol are also prevalent in prison populations $[4,10,13]$. Inmates who commit suicide often have had previous contact with mental health services before imprisonment; in some cases, they have had their symptoms correctly recognised during reception screening evaluations $[10,14]$.

Not all suicide attempts are meant to be lethal. For example, oftentimes self-harm is either manipulative or represents a distorted way for inmates to express their needs [1], thus increasing the difficulty in defining their actual risk for suicide.

Globally, hanging is the preferred method of suicide amongst inmates and psychiatric in-patients, alike, and it is associated with a fatality rate of more than $70 \%$ [1, 15-18]. Hawton et al. reported that it is also the first choice for suicidal prisoners who have previously engaged in self-harming behaviour [19].

Inmates can have access to a wide variety of ligatures in a common prison, such as bras, ropes, belts, scarfs, towels, sheets, clothes, shoelaces and electric cables [15, 20]. They also have access to many possible ligature points (especially in outdated facilities), such as beds, bars, trees, pipes, beams, hooks, toilets, banisters, radiators and cupboards [15].

In Italy, persons under custody are constitutionally granted personal safety and full access to every service provided by the National Health Service (NHS). In harmony with these principles, Italian National Law 354 of 1975 established the necessity for at least one psychiatrist to be employed at every correctional facility [21]. Nevertheless, overcrowding and the lack of specially trained medical staff have made it difficult to address the needs of the prison population [1]. In Italian jails, an inmate can drink up to $0.5 \mathrm{~L}$ of wine or $1 \mathrm{~L}$ of beer every day [22]. Inmates at a high risk for suicide often live in solitary confinement and are under constant surveillance [1].

In this paper, we present two cases of suicide that were committed by hanging in which the victims used their underwear as the ligature. To the best of our knowledge, only a few authors have described underwear as a possible means for self-harm in this context [23], and no previous paper has focused on the forensic aspects of prison suicide by underwear, even though it is usually available even to inmates who are at high risk for suicide. We aim to discuss whether or not solitary confinement can jeopardise the safety of high-risk inmates and to hypothesise new strategies that may aid in the prevention of prison suicides and serve to better protect prisoners' health and safety rights.

\section{Case 1}

A young 24-year-old North African man was found hanged in his confinement cell in a semi-sitting position. He had used the elastic band of his underwear (35-cm long, 3-cm wide) as the ligature and the bars of his cell window as the ligature point. The inmate had been transferred to the prison 5 days before he hanged himself.

During his reception screening, the inmate was identified as a highly aggressive person who had been prescribed psychotropic medication (clonazepam) and who had made contact with mental health services prior to his imprisonment. While he had never been diagnosed with a specific mental illness, during his imprisonment, he continuously showed traits suggestive of DSM-5 cluster B personality disorders (repeated physical fights, irritable aggressiveness, severely impaired impulse control and affective instability with marked mood reactivity). He presented episodes of agitation, excessive violence and threatening behaviour against the environment and others. The facility's psychiatrists prescribed benzodiazepines (clonazepam and diazepam) and a first-generation antipsychotic medication (chlorpromazine).

The day before his imprisonment, he was involved in a physical altercation, and he had complained of chest pain since then. He underwent two X-ray examinations, but because no fracture was clearly identified, he was only given pain relievers. The night before his suicide, he presented severe violent behaviour against objects, and he became physically violent a second time, forcing the facility's staff to sedate him with benzodiazepines (clonazepam and diazepam) and an antipsychotic drug (chlorpromazine). He was visited again for his health issues the following day. About 3 hours after this examination, he committed suicide.

A forensic autopsy was ordered by the prosecutor. At external examination, the corpse was dressed in ordinary clothes, and some pills (benzodiazepines) were found in the pocket of his trousers. He was partially edentulous, and he had two old scars on his head. The ligature mark on his neck was 44.5$\mathrm{cm}$ long, $0.5-\mathrm{cm}$ wide (narrower near the edges), oblique, discontinuous and interrupted in the left lateral region (near the ipsilateral auricle). The local skin area was red-brown, hard and parchment-like. The mark was wider and deeper in the right anterolateral part. In this area, signs of a vital reaction caused by rubbing were particularly clear. The edges of the ligature mark could be localised to the left laterocervical region, $3 \mathrm{~cm}$ from the ipsilateral ear (Fig. 1). An old, long scar was detected slightly under the compressed region, and the neck showed no signs of preternatural motility. The left forearm presented several old scars on its surface. The chest was bruised and abraded. At dissection, the right greater horn of the hyoid bone was fractured, and the surrounding tissues showed exiguous signs of vital reaction. A rib was broken in correspondence 


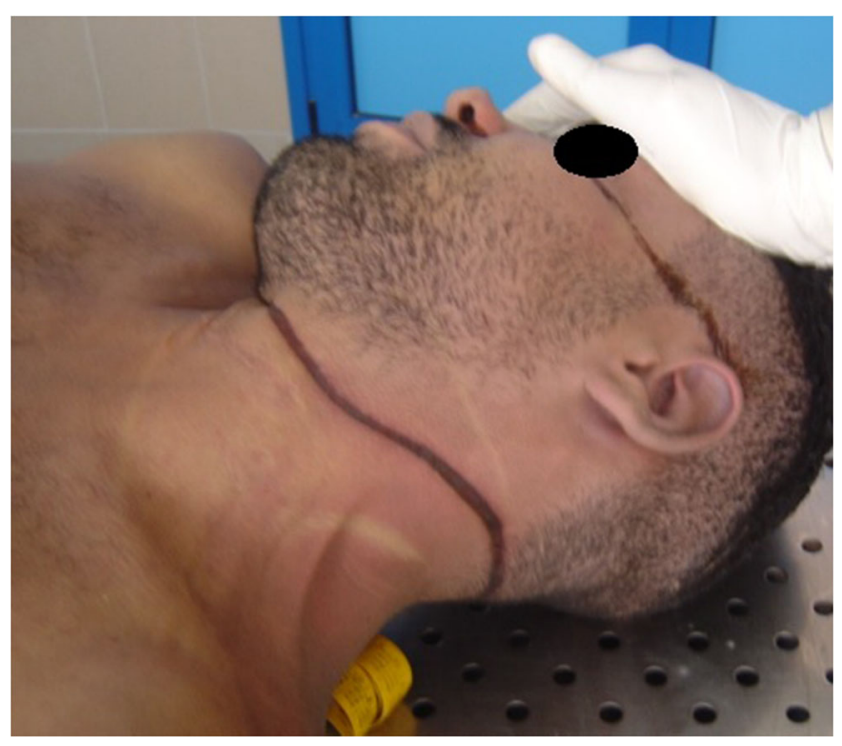

Fig. 1 Case 1 image showing edges of the ligature mark localised to the left laterocervical region, $3 \mathrm{~cm}$ from the ipsilateral ear

to the area that the inmate had referred to as painful. Toxicological analysis demonstrated urinary traces of benzodiazepines.

\section{Case 2}

After 7 days in a new prison, a 35-year-old Italian woman, who had been accused of violating the conditions of her parole, was found hanged in a confinement cell while on remand. She used the elastic band of her underwear as the ligature and the bars of her cell window as the ligature point. She was nulliparous; prior to isolation, she had chosen to have no social interactions with her family or other inmates. She had been diagnosed with alcohol addiction, bipolar I disorder and borderline personality disorder. Before imprisonment, she had made contact with several mental healthcare facilities. She had a history of suicide attempts and of problematic adhesion to psychiatric treatment. Previous alcohol detoxification programmes had been unsuccessful.

At previous prisons, she had attempted suicide several times; just after her transfer, she had tried to hang herself with an electric cable from a television set. After psychiatric visitation, she was deprived of her clothing, isolated in a cell without furniture and placed under constant observation. The inmate claimed that her self-harm was an act of protest because she wanted to be treated in a hospital of her choice. In her cell, the inmate manifested paranoid thoughts and continuous mood swings (with depressive symptoms and marked irritability), and she tried to harm herself by hitting her head against the cell walls. Moreover, she was aggressive toward the prison officers and the operators of the pedagogical services. She arbitrarily refused to take certain medications that she considered to be dangerous to her health.

She denied her addiction to alcohol but craved and continuously asked for beer. She also threatened to commit suicide and to go on a hunger strike in order to obtain transfer into a general hospital. Before her suicide, she underwent treatment with olanzapine (a second-generation antipsychotic), gabapentin (an antiepileptic drug used as mood stabiliser) and delorazepam (benzodiazepine). In the seventh day of detention, her observation was interrupted for less than $15 \mathrm{~min}$, which gave her sufficient time to successfully commit suicide. A forensic autopsy was ordered by the prosecutor. At external examination, the ligature mark was red, oblique and discontinuous and interrupted at the left nuchal region. It was $4 \mathrm{~cm}$ under the left ear lobe and $5 \mathrm{~cm}$ under the right earlobe; its maximum width was $0.5 \mathrm{~cm}$ (Fig. 2). It was also hard to the touch. At dissection, the right greater horn of the hyoid bone was found to be fractured.

\section{Discussion}

As previously described, inmates can use their underwear to commit suicide. In our opinion, this data is important because this kind of garment, which is potentially lethal, is normally made available to all inmates.

From a forensic point of view, there are several similarities between the two cases. In both inmates, the ligature mark was atypical (the knot was positioned in the left lateral region of the neck), narrow and hard to the touch. These two last characteristics are due to the fact that the traction force exerted by the hanged mass stretches the elastic band of the underwear, making it narrower. According to the physical definition of

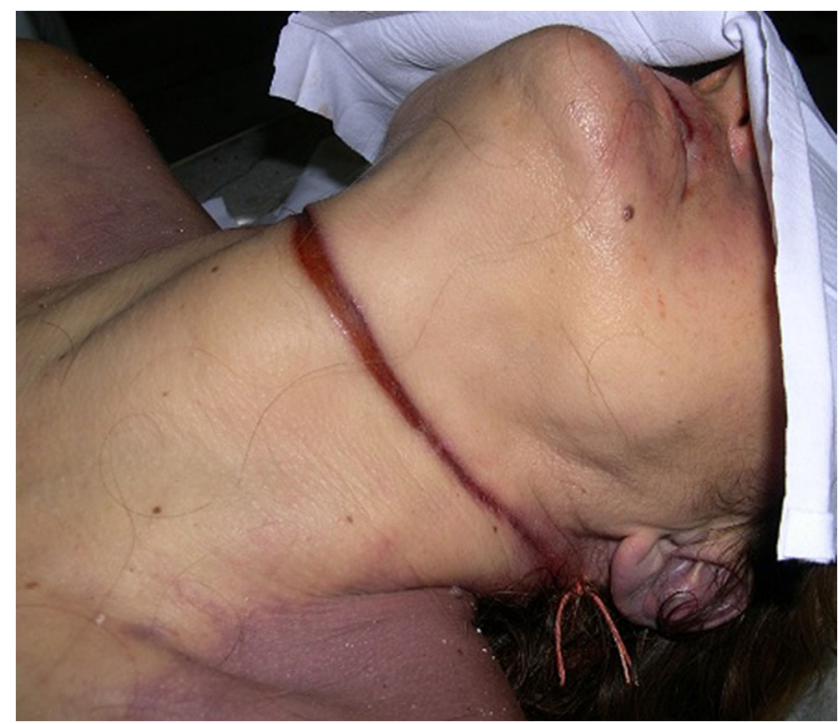

Fig. 2 Case 2 image showing ligature mark $4 \mathrm{~cm}$ under the left ear lobe and $5 \mathrm{~cm}$ under the right earlobe 
pressure (the ratio of force to the surface area over which it is applied), the reduction of the region covered by the ligature increases the mechanical insult to the skin, thus explaining the hard consistence of the ligature mark. The absence of significant peri-ligature injuries (such as blisters, rope burn, ecchymosis and abrasions) reflects the low friction coefficient of elastic materials used for underwear. In these two cases, the exiguous grooving of ligature marks indicates a short suspension time, helping to confirm that both victims were promptly discovered [24]. Internally, the ligature marks corresponded to the fracture of the right greater horn of the hyoid bone, a relatively common finding in the cases of hanging that is compatible with the position of the knots [25].

Our first consideration when comparing the two cases is that both inmates had very similar profiles: they were both young, physically aggressive and in their first week at a new facility. Moreover, they both had histories of mental disorders, psychiatric hospitalisations and prescriptions to psychotropic medications. At reception screening, both were recognised as having suicidal tendencies. In addition, both inmates were isolated, and interdisciplinary treatment programmes had been activated to monitor their hostility.

The inmates in both cases presented many traditional suicidal tendencies: they were addicted to alcohol, suffered from psychiatric disorders, had an alarming history of suicidality, had been confined into an isolation cell and had been alienated both inside and outside of prison. In the general population as well as the prison population, persons with bipolar disorders show an increased risk for suicide [5, 10]. However, while we think pharmacological treatment and the early and correct psychiatric evaluation of the risk of suicide are necessary, it is our opinion that these measures cannot sufficiently prevent suicide. Rather, we believe that complete isolation and depriving inmates of their clothing further impair their self-esteem, human dignity and their ability to cope with the extreme social and psychological environment of the prison system.

Finding a cellmate fit to live with a high-risk inmate is difficult, but essential. Marzano et al. demonstrated that female inmates on remand were more vulnerable to suicide when they had been isolated to a single cell [26]. In case 2, the inmate had previously violated her terms of probation, and this may have indicated a clear need to intensify her efforts for social rehabilitation. We believe that the lack of possible socialisation amongst inmates who are incompatible with the prison system is not only an additional stressor and a failed opportunity for social reintegration but also an aberration, because it makes measures of protection for a person at risk for suicide equivalent to punitive isolation. Furthermore, this isolationist strategy betrays the principles that have inspired Italian laws to regulate the management of correctional facilities [22]. In this regard, we think that the potential for Italian inmates to drink alcohol is questionable, due to its relationship with prison suicides and mental health in general [10]. In case
2 , the correct management of the inmate's addiction was neglected, which led her to commit further acts of verbal and physical protest in order to obtain alcohol.

It is our opinion that, in both cases, the surveillance of the patients' adherences to psychiatric medication deserves attention. For instance, while the inmate from case 1 stored free pills in his pocket, the inmate from case 2 inconsistently adhered to their prescribed treatment. In Italy, treatment without consent is only permissible in extreme circumstances, leaving psychiatric patients with the complete freedom to manage their intake of the drugs that they have been prescribed. According to existing evidence, there is a significant connection between non-adherence to treatment and risk of suicide [27].

As previously described, most suicides occur within the first year of imprisonment and climax within the first days or weeks of detention [1, 28]. During this initial period, inmates must cope with the prison environment and its restrictions to their personal freedom. In both of the cases we described, suicide was committed within the first week of each inmate's detention. Therefore, adequate and comprehensive services should be made available to inmates as soon as possible. Custodial and medical staff should also be trained to properly manage socially, clinically and psychologically complex situations. This is particularly true for women and foreigners, who could have specific needs that do not apply to men or individuals who were born in the country in which they are imprisoned. Unfortunately, the overcrowding of prisons (a global problem) can hinder a facility's fulfilment of these duties, which can increase the risk of suicide [1].

In regard to the presence of potential ligatures and ligature points in cells, in each of the cases presented in this paper, underwear was tied to the window bars in the inmates' cells. In this respect, it is our belief that the removal of cell furniture is insufficient for inmates who are at high risk for suicide; rather, when possible, the design of cells and recreational areas should be specifically engineered to prevent suicide attempts. In particular, it is important to remove or prevent an inmate from accessing certain objects, such as bars, pipes and hooks.

A correlative analysis of the safety issues and hygienic, economic and psychological needs of inmates at high risk of suicide could lead to the introduction of special prison uniforms made of materials that are poorly resistant to traction and that lack belts, cords or elastic bands.

According to current evidence, while asphyxia is an uncommon cause of death in suicides committed by the general population, typically, prison hangings are asphyxial. Asphyxia can cause loss of consciousness after 8 to $18 \mathrm{~s}$, permanent brain damage within $3 \mathrm{~min}$ and death in as little as 5 to $7 \mathrm{~min}$ [15, 20, 29-34]. Thus, according to Sauvageau et al., the type of suspension (complete vs. incomplete) does not influence the timing of agonal responses [32]. As 
demonstrated in case 2, checking in on the prisoner every 15 min or interrupting observations for the same period of time can give an inmate more than enough time to successfully commit suicide. This implies that high-risk prisoners in solitary confinement should be constantly monitored, which is a measure that is inhumane and unethical.

In conclusion, it is critical to stress that a significant share of Italian inmates have not been convicted of crimes by a judgement that has the force of res judicata. In other words, 19,690 of the inmates from the national prison population of 56,919 are on remand or have been condemned and are awaiting final judgement [35]. In theory, individuals who have not received final judgement should only be imprisoned in exceptional circumstances and if their health conditions are compatible with detention. Regardless, overuse of remand is often justified to decrease the risk of repeated offences [36]. We think that the imprisonment of individuals who are at high risk of suicide should be avoided, at least until final judgement; moreover, suicidal issues should preferentially receive adequate management outside of correctional facilities (for example, in common mental health institutes and halfway houses). Obviously, the criminal records and psychological statuses of individual candidates should be carefully examined before any decisions are made.

\section{Conclusion}

In our opinion, detention should be a chance for inmates to normalise their antisocial behaviour and provide them with a means of future reintegration. Instead, in Western countries, detention seems to involuntarily be a new form of torture that can severely jeopardise the physical and mental health of inmates.

The common adoption of measures of punishment, such as solitary confinement, for inmates at high risk of suicide is questionably ethical, often impractical and always counterproductive. Indeed, almost anything can be used as a ligature, and a few minutes without surveillance is a sufficient amount of time for an inmate to successfully commit suicide by hanging. In spite of the need to develop a specific design for prison cells assigned to inmates that commit selfharm or that prove to be socially aggressive, it is our opinion that mandatory social and clothing deprivation is inhumane. We believe that the development of new kinds of garments for high-risk inmates (without elastic and resistant to traction materials), addiction prevention and improvements in reaction times, surveillance over medication adherence (avoiding self-medication) and access to social and psychological services and treatments could help solve this very complex problem. While the overcrowding of prisons is an obvious obstacle to these suggestions, the establishment of evidence-based standardised protocols for the management of suicidal inmates and the introduction of alternative forms of detention for the most alarming persons (such as custody in safe and "normal" milieus, like general hospitals) could be a step in the right direction.

\section{References}

1. National Bioethics Committee, Presidency of the Council of Ministers, Italy (2010) Suicides in prison. Bioethical indications. Italy, 25 June 2010

2. Konda S, Reichard AA, Tiesman HM (2012) Occupational Injuries among U.S. Correctional Officers 1999-2008. J Saf Res 43(3): 181-186

3. Duthé G, Hazard A, Kensey A, Shon JL (2013) Suicide among male prisoners in France: a prospective population-based study. Forensic Sci Int 233(1-3):273-277

4. Fazel S, Hayes AJ, Bartellas K, Clerici M, Trestman R (2016) Mental health of prisoners: prevalence, adverse outcomes, and interventions. Lancet Psychiatry 3(9):871-881

5. Gooding P, Tarrier N, Dunn G, Shaw J, Awenat Y, Ulph F, Pratt D (2015) The moderating effects of coping and self-esteem on the relationship between defeat, entrapment and suicidality in a sample of prisoners at high risk of suicide. Eur Psychiatry 30(8):988-994

6. Zlodre J, Fazel S (2012) All-cause and external mortality in released prisoners: systematic review and meta-analysis. Am J Public Health 102(12):e67-e75

7. Rivlin A, Hawton K, Marzano L, Fazel S (2013) Psychosocial characteristics and social networks of suicidal prisoners: towards a model of suicidal behaviour in detention. PLoS ONE 8(7):e68944

8. Department of Penitentiary Administration, Ministry of Justice, Italy (2016) Critical events in prison facilities: 1992-2016. Italy, 31 December 2016

9. Ministry of Justice, United Kingdom (2017) Safety in custody statistics bulletin, England and Wales, deaths in prison custody to December 2016, assaults and self-harm to September 2016. United Kingdom, 26 January 2017

10. Shaw J, Baker D, Hunt IM, Moloney A, Appleby L (2004) Suicide by prisoners. National clinical survey. Br J Psychiatry 184:263-267

11. Fruehwald S, Matschnig T, Koenig F, Bauer P, Frottier P (2004) Suicide in custody: case-control study. Br J Psychiatry 185:494498

12. Roma P, Pompili M, Lester D, Girardi P, Ferracuti S (2013) Incremental conditions of isolation as a predictor of suicide in prisoners. Forensic Sci Int 233(1-3):e1-e2

13. Zoccali R, Muscatello MR, Bruno A, Cambria R, Cavallaro L, D'Amico G, Isgrò S, Romeo V, Meduri M (2008) Mental disorders and request for psychiatric intervention in an Italian local jail. Int $\mathrm{J}$ Law Psychiatry 31(5):447-450

14. Martin MS, Colman I, Simpson AIF, McKenzie K (2013) Mental health screening tools in correctional institutions: a systematic review. BMC Psychiatry 13:275

15. Gunnell D, Bennewith O, Hawton K, Simkin S, Kapur N (2005) The epidemiology and prevention of suicide by hanging: a systematic review. Int J Epidemiol 34(2):433-442

16. Sarchiapone M, Mandelli L, Iosue M, Andrisano C, Roy A (2011) Controlling access to suicide means. Int J Environ Res Public Health 8(12):4550-4562

17. Kapur N, Hunt IM, Windfuhr K, Rodway C, Webb R, Rahman MS, Shaw J, Appleby L (2013) Psychiatric in-patient care and suicide in 
England, 1997 to 2008: a longitudinal study. Psychol Med 43(1): 61-71

18. Gauthier S, Reisch T, Bartsch C (2015) Swiss prison suicides between 2000 and 2010. Crisis 23:1-7

19. Hawton K, Linsell L, Adeniji T, Sariaslan A, Fazel S (2014) Selfharm in prisons in England and Wales: an epidemiological study of prevalence, risk factors, clustering, and subsequent suicide. Lancet 383(9923):1147-1154

20. Saukko P, Knight B (2004) Knight's forensic pathology. Hodder Arnold, London

21. Law No. 354, Italy (1975) Norme sull'ordinamento penitenziario e sull'esecuzione delle misure privative e limitative della libertà. Italy, 26 July 1975

22. Decree of the President of the Republic No. 230, Italy (2000) Regulations - Containing provisions on the Penitentiary act and on measures entailing restrictions on, and deprivation of, personal liberty. Italy, 30 June 2000

23. Bardale RV, Dixit PG (2015) Suicide behind bars: a 10-year retrospective study. Indian J Psychiatry 57(1):81-84

24. Tumram NK, Ambade VN, Bardale RV, Dixit PG (2014) Injuries over neck in hanging deaths and its relation with ligature material: is it vital? J Forensic Legal Med 22:80-83

25. Khokhlov VD (2015) Trauma to the hyoid bone and laryngeal cartilages in hanging: review of forensic research series since 1856. Legal Med 17:17-23

26. Marzano L, Hawton K, Rivlin A, Fazel S (2011) Psychosocial influences on prisoner suicide: a case-control study of near-lethal self-harm in women prisoners. Soc Sci Med 72(6):874-883
27. Chapman SCE, Horne R (2013) Medication nonadherence and psychiatry. Current Opinion in Psychiatry 26(5):446-452

28. Arboleda-Flòrez J (2009) Mental patients in prisons. World Psychiatry 8:187-189

29. World Health Organization (2007) Preventing suicide in jails and prisons. WHO Document Production Services, Geneva

30. Copeland AR (1989) Fatal suicidal hangings among prisoners in jail. Med Sci Law 29(4):341-345

31. Clément R, Redpath M, Sauvageau A (2010) Mechanism of death in hanging: a historical review of the evolution of pathophysiological hypotheses. J Forensic Sci 55(5):1268-1271

32. Sauvageau A, Laharpe R, King D, Dowling G, Andrews S, Kelly S, Ambrosi C, Guay JP, Geberth VJ (2011) Agonal sequences in 14 filmed hangings with comments on the role of the type of suspension, ischemic habituation, and ethanol intoxication on the timing of agonal responses. Am J Forensic Med Pathol 32(2):104-107

33. Agonal SA (2009) Sequences in four filmed hangings: analysis of respiratory and movement responses to asphyxia by hanging. $\mathrm{J}$ Forensic Sci 54(1):192-194

34. Sauvageau A, LaHarpe R, Geberth VJ (2010) Agonal sequences in eight filmed hangings: analysis of respiratory and movement responses to asphyxia by hanging. J Forensic Sci 55(5):1278-1281

35. Ministry of Justice, Italy (2017) Detenuti presenti italiani e stranierianni 1991-2017. Italy, 30 June 2017

36. Criminal Procedure Code art. 275, Italy (1988) Criteri di scelta delle misure. Italy, 22 September 1988 